\title{
Interculturalidad y educación desde el Sur. Contextos, experiencias y voces
}

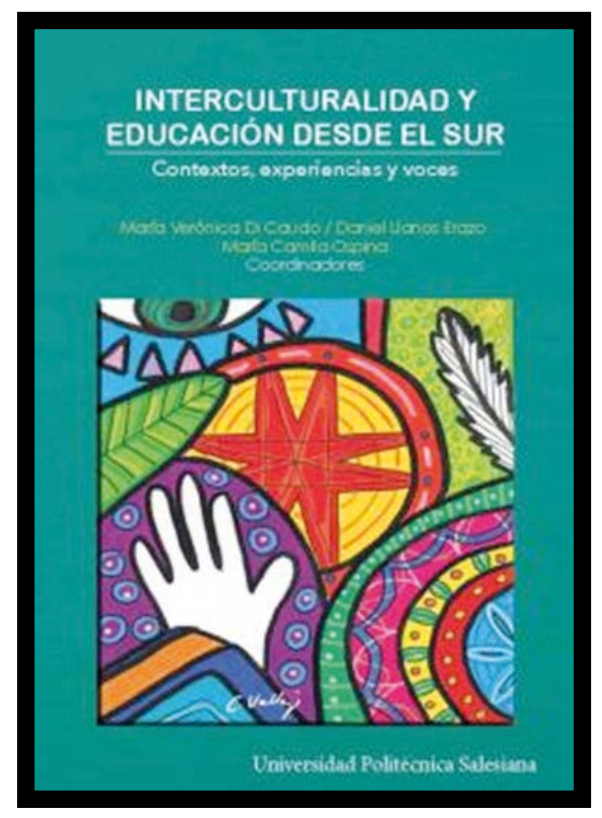

Interculturalidad y educación desde el Sur. Contextos, experiencias y voces María Verónica Di Caudo. Daniel Llanos Erazo. María Camila Ospina Alvarado. [Coordinadores]. CLACSO. CINDE. Abya-Yala, Universidad Politécnica Salesiana. Quito. Octubre de 2016.

Rutas para aproximarnos a la disputa por la interculturalidad desde la educación superior y los jóvenes indígenas en América Latina Interculturalidad y educación desde el Sur. Contextos, experiencias y voces es un libro colectivo que corona once trabajos de investigación realizados por diecisiete autores con diferentes adscripciones institucionales que se articulan a través de grupos de trabajo latinoamericanos en torno al debate actual sobre la Interculturalidad y Educación. Y con ello obligan al lector a pensar simultáneamente en un conjunto de movimientos o desplazamientos teórico-conceptuales, en el despliegue de posicionamientos éticos, filosóficos, políticos y jurídicos, y en el desarrollo de metodologías de investigación novedosas, que nos posibiliten revelar y actuar sobre una diversidad de experiencias, modelos y programas que buscan potenciar los procesos interculturales en el Sur. La obra en su conjunto es un aporte a la creciente producción bibliográfica que se genera en la última década desde la perspectiva crítica de Latinoamérica.

La primera propuesta que tiene el lector es el abordaje de la Interculturalidad y Educación desde el Sur, atendiendo diferentes contextos, experiencias y voces, resultado del "intercambio desde campos disciplinarios y experiencias multisituadas". De ahí que esta obra colectiva trascienda la discusión actual. Resulta significativo que los investigadores jóvenes aquí reunidos -gracias a la convocatoria de los coordinadores- se sitúen en una diversidad de contextos socioculturales y étnico-políticos, y sus trayectorias académicas y colaborativas develen los caminos y experiencias contemporáneas de la interculturalidad desde el Sur. 
Los textos presentados por este grupo de investigadores expresan un fuerte compromiso académico por abrir sendas, campos, espacios, áreas y departamentos de investigación para el abordaje la relación interculturalidad y educación. También manifiestan un sólido compromiso social con las demandas de los pueblos, comunidades y organizaciones étnicas y políticas, así como con las instituciones educativas, académicas y dependencias de gobierno en función de generar y desarrollar procesos educativos interculturales.

Ubicados en las principales tendencias y debates en sus respectivos campos de conocimiento, espacios colaborativos y contextos sociales, étnico y políticos, los autores se emplazan en la perspectiva latinoamericana crítica de las ciencias sociales desde el Sur pensando la interculturalidad como discurso y categoría que tomó fuerza en la región en los últimas cinco décadas. Su propuesta de "comprender la interculturalidad situados en el sur de un continente diverso, heterogéneo pero sobre todo desigual", plantea una diferenciación constitutiva en el conteniente latinoamericano entramada en geografías culturales, étnicas, regionales, socioeconómicas, políticas, etarias y de género. De ahí la importancia de atender las particularidades de los procesos y relaciones interculturales desde una perspectiva relacional, histórica, contextualmente situada y con sujetos, actores o agentes específicos.
Precisamente, el análisis de la producción bibliográfica en la última década revela que el enfoque intercultural, en términos conceptuales, varía en función del contexto, los objetivos y las condiciones que intervienen en su aplicación práctica. Aunque no debemos perder de vista que se sigue implementando de forma preferencial $\mathrm{y}$, a veces, de manera casi exclusiva, en contextos indígenas y rurales como producto y reflejo de la persistencia del indigenismo mexicano, y de la emergencia de los movimientos indígenas latinoamericanos (Bertely et al., 2013: 22).

La interculturalidad aparece como un término analítico y multidimensional, situándose simultáneamente como perspectiva éticafilosófica, epistémica, pedagógica, metodológica, social, política y jurídica.

El libro da cuenta de los desplazamientos que realizan cada uno de los autores por casi todas estas dimensiones, desde sus quehaceres investigativos y desde lecturas especializadas y actualizadas que se insertan en el debate contemporáneo global y regional sobre interculturalidad y educación a fin de descentrar las miradas hacia la educación intercultural desde "abajo" y en el marco de la descolonialidad y perspectiva crítica latinoamericana.

Del prólogo a cargo de Maritza Urteaga Castro Pozo y Luis Fernando García Álvarez 